\title{
Expression of SOX2OT, DANCR and TINCR long non-coding RNAs in papillary thyroid cancer and its effects on clinicopathological features
}

\author{
FADIME MUTLU ICDUYGU ${ }^{1}$, EGEMEN AKGUN $^{2}$, DEMET SENGUL $^{3}$, ASUMAN OZGOZ $^{4}$ and EBRU ALP ${ }^{2}$ \\ Departments of ${ }^{1}$ Medical Genetics, ${ }^{2}$ Medical Biology and ${ }^{3}$ Pathology, Faculty of Medicine, \\ Giresun University, Giresun 28100; ${ }^{4}$ Department of Medical Genetics, Faculty of Medicine, \\ Kastamonu University, Kastamonu 37100, Turkey
}

Received December 8, 2021; Accepted January 19, 2022

DOI: $10.3892 / \mathrm{mmr} .2022 .12636$

\begin{abstract}
Long non-coding RNAs (lncRNAs) are molecules that are $>200$ base pairs long and do not encode a protein. However, they perform important roles in regulating gene expression. Recent studies have revealed that the changes in the expressions of lncRNAs serve a role in the development and metastases of a number of types of cancer. A number of studies have been published on the association of SOX2 overlapping transcript (SOX2OT), differentiation antagonizing non-protein coding RNA $(D A N C R)$ and tissue differentiation-induced non-coding RNA (TINCR) expression with various types of cancer. However, researchers have not yet studied their roles in papillary thyroid cancer or at least, those roles are not clarified. The aim of the present study was to investigate the expression and clinical significance of SOX2OT, DANCR and TINCR in papillary thyroid cancer (PTC). A total of 102 patients with PTC were included in the present study. Reverse transcription-quantitative PCR method was used to determine the relative gene expression levels of lncRNAs and then the relationship between expressions of lncRNAs and clinical characteristics of the subjects was analyzed in detail. Expression levels of SOX2OT $(\mathrm{P}=0.016)$ and DANCR $(\mathrm{P}=0.017)$ increased in the tumor samples in contrast to the normal tissues. No significant difference was observed in the expression level of TINCR $(\mathrm{P}=0.298)$. In addition, SOX2OT expression was associated with micro carcinoma $(\mathrm{P}<0.001)$, tumor size $(\mathrm{P}=0.010)$ and primary tumor $(\mathrm{P}=0.006)$, while
\end{abstract}

Correspondence to: Dr Fadime Mutlu Icduygu, Department of Medical Genetics, Faculty of Medicine, Giresun University, Building B, Yüzbaşı Suyu Caddesi, Gazipasa Yerleskesi, Giresun 28100, Turkey

E-mail: fadimemutlu@yahoo.com

Key words: papillary thyroid cancer, long non-coding RNA, SOX2 overlapping transcript, differentiation antagonizing non-protein coding RNA, tissue differentiation-induced non-coding RNA, reverse transcription-quantitative PCR
$D A N C R$ expression was associated with age $(\mathrm{P}=0.030)$ and micro carcinoma $(\mathrm{P}=0.004)$. The findings of the present study indicated that DANCR may contribute to the development of PTC while SOX2OT may contribute to both the development and progression of PTC.

\section{Introduction}

Thyroid cancer is the most widespread form of endocrine cancers worldwide. Its incidence has been reported to have increased in recent years (1). According to histological features, thyroid cancer can be divided into four subgroups: Papillary, follicular, anaplastic and medullary. Among these subgroups, the most common type $(\sim 80 \%)$ is papillary thyroid cancer (PTC) originating from follicular cells $(2,3)$. Even though current forms of treatment (e.g., surgical intervention and radioactive iodine) can keep this disease under control for a number of patients, it nevertheless has a high morbidity rate; likewise, in some cases, the tumors can be aggressive $(4,5)$. In addition, while it is known that environmental and genetic factors serve a role in development of this disease (6), its pathogenesis is not fully clarified. Therefore, there is a need to elucidate the molecular mechanisms involved in the development of the disease and to discover effective treatment targets, such as biomarkers that can be used in early diagnosis and prognosis prediction.

Long non-coding RNAs (IncRNAs) are molecules that are $>200$ base pairs long and do not encode a protein. However, they perform important roles in regulating gene expression. LncRNAs can regulate the expression of genes involved in processes such as cell cycle, proliferation, differentiation, stem cell differentiation, apoptosis, invasion, migration and autophagy through different mechanisms such as regulation of chromatin structure, transcription, splicing process, post-transcriptional events and interaction with microRNAs $(2,7)$. The changes in the expression of lncRNAs and impairment of their regulatory functions have been associated with a number of diseases, including numerous types of cancer. It has been reported that several IncRNAs (e.g. NEAT1, MALAT1, H19, HOTAIR, BANCR, PTCSC3) are associated with the development and progression of thyroid cancer $(3,8)$. 
The SOX2 overlapping transcript (SOX2OT) gene is located in the $3 \mathrm{q} 26.3$ region and contains the $S O X 2$ gene in its intronic region. This gene serves a key role in maintaining both pluripotency and self-renewal properties of embryonic stem cells $(9,10)$. Many studies have revealed that the increase in SOX2OT expression in cancer cells induces SOX2 expression and this in turn contributes to tumorigenesis (11-14). The changes in SOX2OT expression have been associated with a number of cancers such as lung, breast, esophageal, gastric, hepatocellular and ovarian (10). However, no study has been published so far investigating the relationship between the expression level of SOX2OT and thyroid cancer, to the best of the authors' knowledge. Therefore, this association required investigation.

Differentiation antagonizing non-protein coding RNA (DANCR), localized on chromosome 4 , is 855 base pairs long and helps suppress progenitor cell differentiation (15). The relationship between $D A N C R$ and tumorigenesis and clinicopathological features of the tumors have been investigated in relation to various types of cancer such as hepatocellular, gastric, colorectal, breast and lung cancer (16-20). It has been reported that $D A N C R$ is an oncogenic lncRNA that is overexpressed in tumor tissues and is associated with poor prognostic factors (16). In molecular studies, it has been demonstrated that $D A N C R$ induces proliferation, migration, invasion, metastasis, angiogenesis and drug resistance and inhibits apoptosis $(16,21)$. There are a few studies reporting that its expression decreases in some tumors and even acts as a tumor suppressor $(22,23)$. In the literature, only one study examined the relationship between $D A N C R$ expression and thyroid cancer and reported that the expression of $D A N C R$ decreases in thyroid cancer (23). Therefore, the relationship between $D A N C R$ and thyroid cancer and its clinicopathological features requires investigation.

Tissue differentiation-induced non-coding RNA (TINCR), which is $\sim 3.7 \mathrm{~kb}$ long, is localized on chromosome 19. TINCR regulates the expression of genes that serve a role in epidermal differentiation. The changes in TINCR expression have been found in esophageal, breast, colon, lung, prostate and bladder cancers and have associated with tumorigenesis $(24,25)$. Only one study has been published that evaluated TINCR expression in thyroid cancer, to the best of the authors' knowledge. In this study, the Cancer Genome Atlas (TCGA) RNA sequencing data for PTC was examined and it was reported that TINCR was one of a number of lncRNAs whose expression increased in thyroid tumor tissue (26). Therefore, the relationship between development of thyroid cancer, clinicopathological features and TINCR expression needs to be supported by other data.

The aim of the present study was to investigate the relationship between expressions of DANCR, TINCR, SOX2OT IncRNAs and development and clinopathological features of PTC.

\section{Materials and methods}

Patients. A total of 112 PTC patients who had undergone a thyroidectomy between January 2015 and December 2020 at Giresun University's Faculty of Medicine were included in this study. Of the 102 patients included in this study, 21 were male and 81 were female. Their age range was 23-85 (median 51). The pathology department histopathologically examined the tumor samples and confirmed the diagnosis of PTC. Those samples (tumor and adjacent non-cancerous thyroid tissue) were obtained from formalin-fixed paraffin-embedded (FFPE) tissue blocks that were archived in the pathology department. The patients included in the study upon examination of the patient records were selected from the subjects who had not undergone chemotherapy, radiotherapy, or other cancer treatments before surgery. As a result of spectrophotometric measurements performed after RNA isolation, 10 patients were excluded from the study because RNA quality was not at optimum level (A260/A280 ratio of 1.8-2.1) and the expression analysis was performed on samples taken from the 102 patients. The present study was approved by Giresun University's Faculty of Medicine Clinical Trials Ethics Committee (approval no. 2018-06-10).

RNA isolation from FFPE tissue samples and cDNA synthesis. After removing the excess paraffin, 4-5 $5 \mu \mathrm{m}$-thick sections were taken from the FFPE tissue blocks of the patients and then transferred into $1.5 \mathrm{ml}$ sterile micro centrifuge tubes. Total RNA isolation was conducted using an RNeasy FFPE kit (Qiagen $\mathrm{GmbH}$ ), in accordance with the manufacturer's protocol. The quality and the concentration of the RNA samples were assessed by measuring the ratio of the absorbances at $260 / 280 \mathrm{~nm}$ on a NanoDrop One/OneC Microvolume UV-Vis Spectrophotometer (Thermo Fisher Scientific, Inc.). Then the integrity of the RNA samples was analyzed using $1 \%$ agarose gel electrophoresis. Then, the samples that had poor RNA quantity and quality were excluded from the study. All samples were kept at $-80^{\circ} \mathrm{C}$ for further research. The cDNA synthesis was carried out using the RevertAid RT Reverse Transcription kit (Thermo Fisher Scientific, Inc.), in accordance with the manufacturer's protocol.

Reverse transcription-quantitative $(R T-q) P C R$ analysis. Expression analysis of lncRNAs was performed using a LightCycler 480 SYBR-Green I Master (Roche Diagnostics $\mathrm{GmbH}$ ) and specific primer pairs according to the manufacturer's protocol on the LightCycler 480 Real-Time PCR system (Roche Diagnostics $\mathrm{GmbH}$ ). $\beta$-actin was used as an internal control to normalize the expression of lncRNAs. The primer pairs for RT-qPCR were: SOX2OT, Forward 5'-GTAAGG CGATGTGGGTGAAG-3'; Reverse 5'-AGTTGAAGGAGC TTGCAGTT-3'; DANCR, Forward 5'-CTGCATTCCTGA ACCGTTATCT-3'; Reverse 5'-GGGTGTAATCCACGTTTC TCAT-3'; TINCR, Forward 5'-AGATGACAGTGGCTGGAG TTGTCA-3'; Reverse 5'-TGTGGCCCAAACTCAGGGATA CAT-3'; $\beta$-actin, Forward 5'-TCTACAATGAGCTGCGTG TG-3'; Reverse 5'-GGTCTCAAACATGATCTGGGT-3' The thermocycling conditions were: $95^{\circ} \mathrm{C}$ for $5 \mathrm{~min}, 6$ cycles of $95^{\circ} \mathrm{C}$ for $10 \mathrm{sec}$ and $57^{\circ} \mathrm{C}$ for $25 \mathrm{sec}, 45$ cycles of $95^{\circ} \mathrm{C}$ for $10 \mathrm{sec}, 57^{\circ} \mathrm{C}$ for $10 \mathrm{sec}$ and $72^{\circ} \mathrm{C}$ for $10 \mathrm{sec}$. All samples were tested in triplicate. Relative gene expression levels in lncRNAs were calculated using the $2^{-\Delta \Delta \mathrm{Cq}}$ method (27).

Statistical analysis. Statistical analyses were performed using SPSS 15.0 (SPSS, Inc.). Continuous variables were expressed as mean \pm standard deviation. The expression levels of SOX2OT, $D A N C R$ and TINCR in tumor and adjacent normal thyroid tissues 

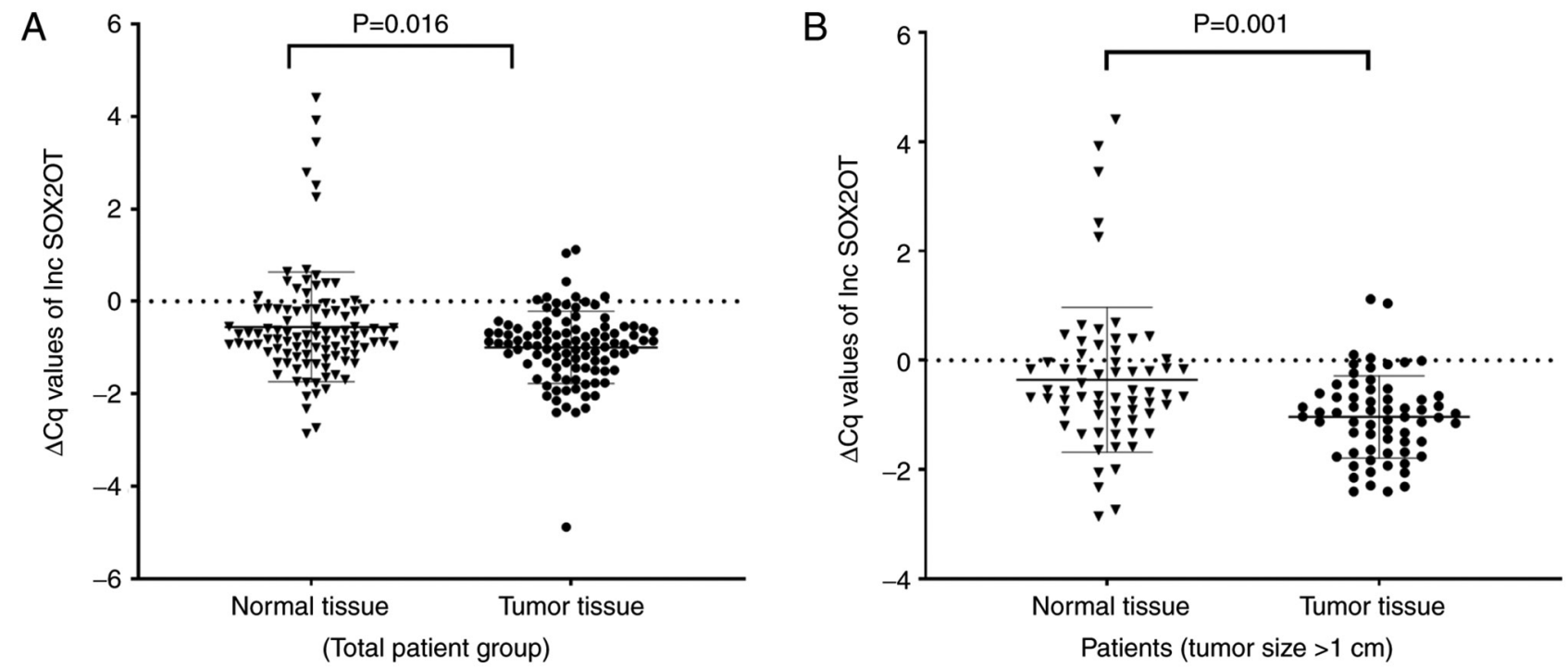

Figure 1. Expression of SOX2OT lncRNA in tumor and normal tissue. (A) The comparisons of lncRNA SOX2OT relative expression levels between normal and tumor tissues of the total patient group $(\mathrm{n}=102)$. (B) The comparisons of IncRNA SOX2OT relative expression levels between normal and tumor tissues of patients whose tumor size was $>1 \mathrm{~cm}(\mathrm{n}=66)$. All of the data are presented as the mean \pm standard deviation. Wilcoxon signed-rank test was used for statistical analysis. $\mathrm{P}<0.05$ was considered to indicate a statistically significant difference. lnc, long non-coding.
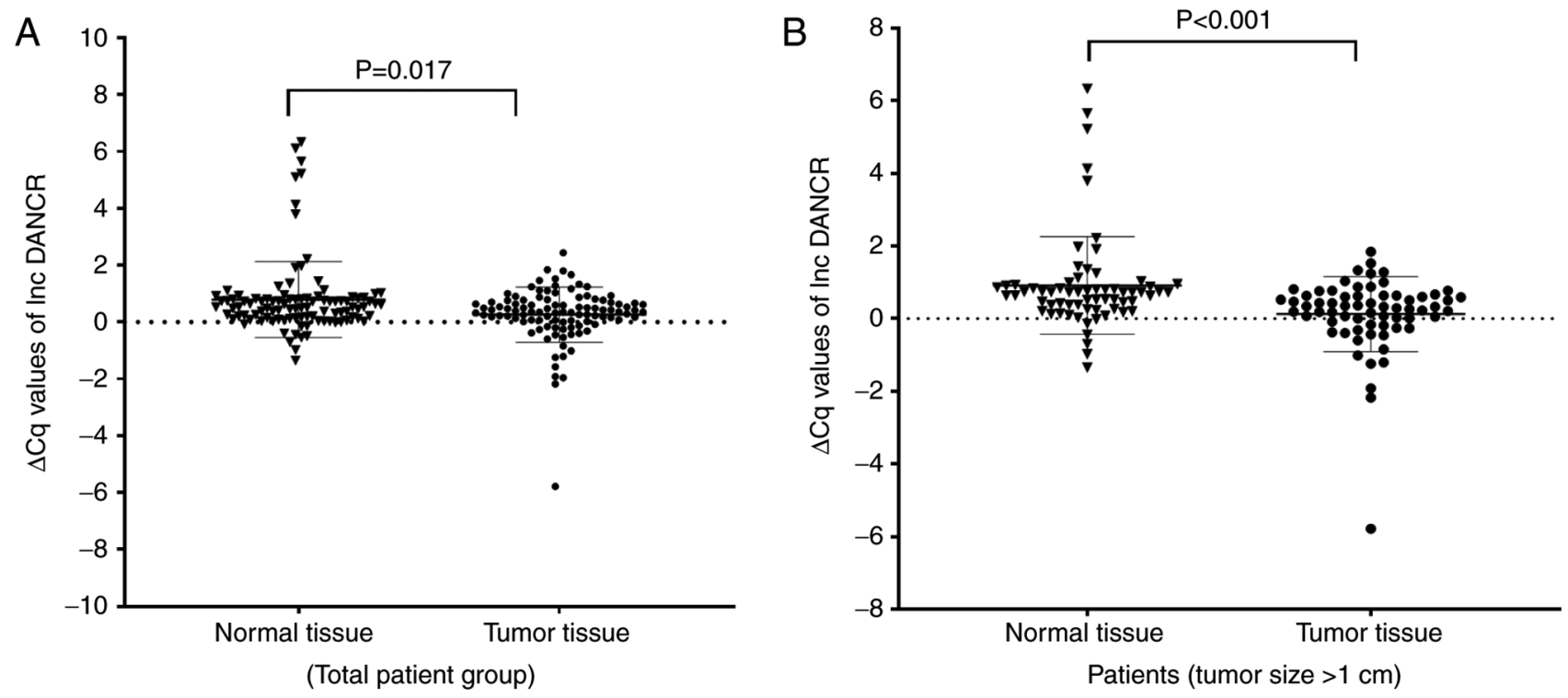

Figure 2. Expression of DANCR lncRNA in tumor and normal tissue. (A) The comparisons of lncRNA DANCR relative expression levels between normal and tumor tissues of the total patient group ( $\mathrm{n}=102)$. (B) The comparisons of lncRNA DANCR relative expression levels between normal and tumor tissues of patients whose tumor size is larger than $1 \mathrm{~cm}(\mathrm{n}=66)$. All of the data are presented as the mean \pm standard deviation. Wilcoxon signed-rank test was used to analyze the statistics. $\mathrm{P}<0.05$ was considered to indicate a statistically significant difference. lnc, long non-coding.

were compared using the Wilcoxon signed-rank test. The patient group was divided into two subgroups (low expression and high expression) according to median IncRNA expression values to determine the relationship between the lncRNA expressions and clinicopathological features in more detail. Categorical data were compared using the chi-square test. $\mathrm{P}<0.05$ was considered to indicate a statistically significant difference.

\section{Results}

Expression levels of SOX2OT, DANCR and TINCR in PTC tissues. RT-qPCR was performed to determine the expression of SOX2OT, DANCR and TINCR lncRNAs in tumor and adjacent noncancerous thyroid tissue samples. The data revealed that SOX2OT (fold change: $2.03, \mathrm{P}=0.016, \mathrm{Z}=-2.405$ ) and $D A N C R$ (fold change: $3.23, \mathrm{P}=0.017, \mathrm{Z}=-2.392$ ) expression significantly increased in the tumor tissues compared with adjacent noncancerous thyroid tissues (Figs. 1A and 2A). On the other hand, no significant change was observed in the expression of TINCR (fold change: $-1.39, \mathrm{P}=0.298, \mathrm{Z}=-1.040$; Fig. 3A).

The relationship between expression levels of SOX2OT, DANCR and TINCR and the clinicopathological features 

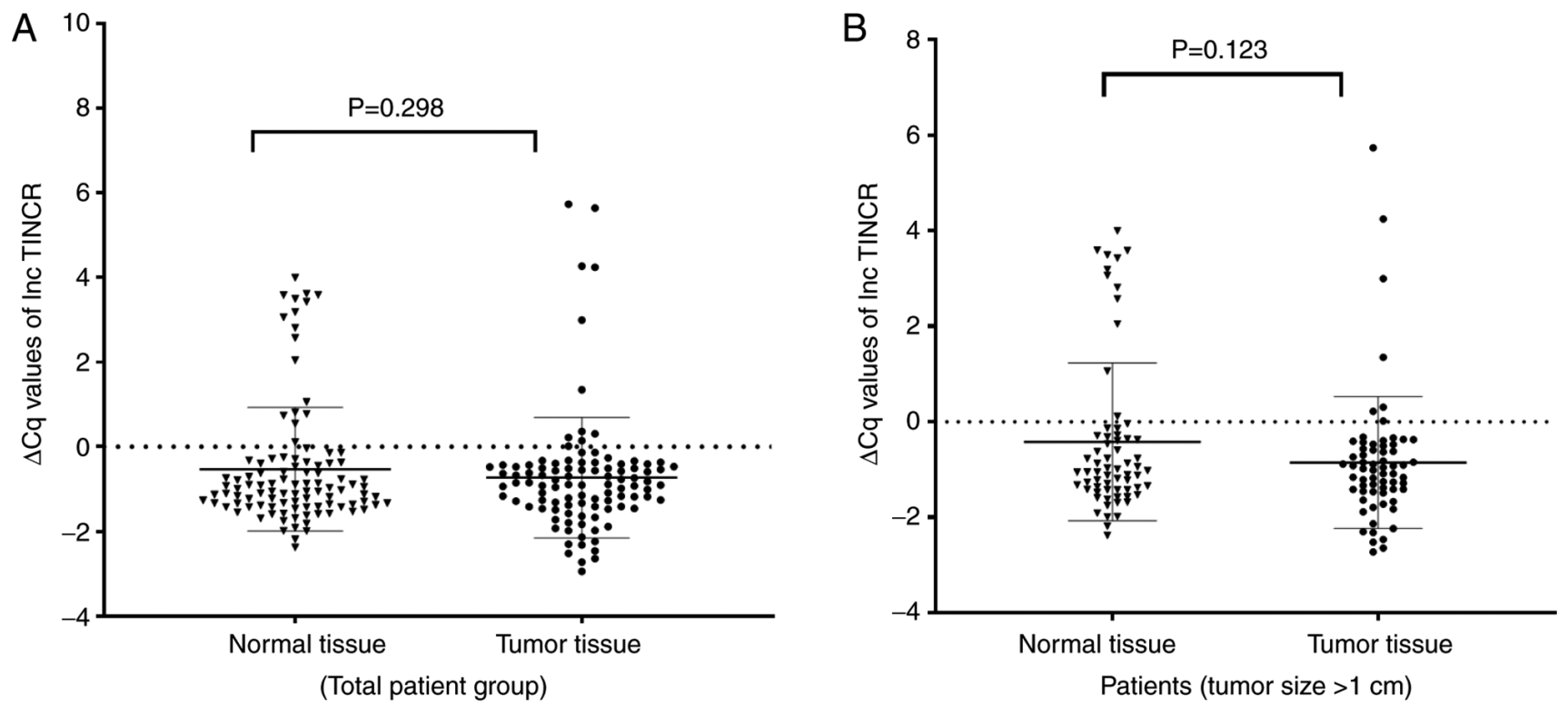

Figure 3. Expression of TINCR lncRNA in tumor and normal tissue. (A) The comparisons of lncRNA TINCR relative expression levels between normal and tumor tissues of the total patient group ( $\mathrm{n}=102)$. (B) The comparisons of lncRNA TINCR relative expression levels between normal and tumor tissues of patients whose tumor size larger is than $1 \mathrm{~cm}(\mathrm{n}=66)$. All of the data are presented as the mean \pm standard deviation. Wilcoxon signed-rank test was used for statistical analysis. $\mathrm{P}<0.05$ was considered to indicate a statistically significant difference. lnc, long non-coding.

of PTC. The patient group was divided into high and low expression subgroups according to the median expression values of lncRNAs in order to assess the relationship between clinicopathological features and expressions of lncRNAs. Accordingly, there was a statistically significant correlation between the SOX2OT expression level and microcarcinoma $(\mathrm{P}<0.001)$, tumor size $(\mathrm{P}=0.010)$, primary tumor $(\mathrm{P}=0.006$; Table I) and between the DANCR expression level and age $(\mathrm{P}=0.030)$, microcarcinoma $(\mathrm{P}=0.004)$ (Table II). A significant correlation was found between the expression level of TINCR and primary tumor $(\mathrm{P}=0.029$; Table III). Since the findings of the present study revealed a significant correlation between the expression levels of lncRNAs and tumor size, a separate evaluation was carried out only in patients who had either papillary microcarcinoma or papillary carcinoma with a tumor size $>1 \mathrm{~cm}$. There was no significant difference in the expression levels of SOX2OT $(\mathrm{P}=0.198, \mathrm{Z}=-1.288)$, DANCR $(\mathrm{P}=0.162, \mathrm{Z}=-1.398)$, or TINCR $(\mathrm{P}=0.637, \mathrm{Z}=-0.471)$ between the tumor and adjacent normal tissues in the patients with papillary microcarcinoma. On the other hand, when evaluating only papillary carcinoma samples (tumor size $>1 \mathrm{~cm}$ ), it was observed that differences in $\operatorname{SOX} 2 O T(\mathrm{P}=0.001, \mathrm{Z}=-3.440)$ and DANCR $(\mathrm{P}<0.001, \mathrm{Z}=-3.830)$ expression levels between tumor and normal tissues became more significant (Figs. 1B and 2B). Again, no significant change was observed in the expression level of TINCR $(\mathrm{P}=0.123, \mathrm{Z}=-1.543$; Fig. 3B).

\section{Discussion}

Although prognosis of PTC is good, diagnostic biomarkers and prognostic predictors are still required (28). Recent studies have focused on lncRNAs as one of the most important molecular biomarkers for various types of cancer and revealed that lncRNAs have important roles in the development and progression of certain cancers $(29,30)$. However, there are few studies specifically investigating the relationship between thyroid cancer and IncRNAs $(23,26,28)$. In the present study, the relationship between the development and clinicopathological features of PTC and expression levels of SOX2OT, $D A N C R$ and TINCR was assessed. To the best of the authors' knowledge, the present study is the first attempt to investigate the association between expression level of SOX2OT and PTC.

Some studies have indicated that SOX2OT lncRNA contributes to tumorigenesis via different mechanisms (11,31). For example, it regulates the expression of the $S O X 2$ gene, which is located in its intronic region and has a key role in regulating the pluripotency properties of embryonic stem cells (32). In addition, SOX2OT acts as a miRNA sponge. In a number of studies, it has been reported that it regulates the expression of genes involved in tumorigenesis, especially by binding to tumor suppressor miRNAs $(12,14,33)$. Li et al (11) reported that SOX2OT interacts with epigenetic regulators or directly binds to the transcription factors and destabilizes them. Studies have revealed that SOX2OT is an oncogene and its expression increases in esophageal squamous cell, bladder, nasopharyngeal, prostate, non-small-cell lung, gastric and hepatocellular cancer alongside glioma $(10,11)$. Similarly, the present study revealed that SOX2OT expression increased significantly in the PTC tumor samples compared with the adjacent normal tissues. This suggested that the increase in the expression of SOX2OT may be associated with the tumorigenesis process of PTC.

Expression of miR-204 is downregulated in PTC, breast and cervical cancer and it acts as a tumor suppressor (34). On the other hand, SOX2OT contains a binding site for miR-204 and acts as a sponge for this miRNA (11). Similarly, some studies have reported that miR-132 and miR-122 have tumor suppressor roles in PTC by suppressing FOXA1 and DUSP4 expression, respectively $(35,36)$. SOX2OT binds to these two miRNAs and suppresses their expression (11). When the results of the present study were compared with those of the aforementioned studies, 
Table I. Association between expression level of SOX2OT and clinicopathological characteristics of patients with PTC. Low/high decided by the median expression of SOX2OT. Chi square test was used for statistical analysis.

\begin{tabular}{|c|c|c|c|c|c|}
\hline \multirow[b]{2}{*}{ Characteristics } & \multirow[b]{2}{*}{ Number of patients } & \multicolumn{2}{|c|}{$\begin{array}{c}S O X 2 O T \\
\text { expression }\end{array}$} & \multirow[b]{2}{*}{ P-value } & \multirow[b]{2}{*}{ Odds ratio $(95 \% \mathrm{CI})$} \\
\hline & & Low & High & & \\
\hline Age, years & & & & 0.759 & $1.143(0.490-2.680)$ \\
\hline$<45$ & 30 & 16 & 14 & & \\
\hline$\geq 45$ & 72 & 36 & 36 & & \\
\hline \multicolumn{6}{|l|}{ Sex } \\
\hline Female & 81 & 42 & 39 & 0.730 & $1.185(0.450-3.100)$ \\
\hline Male & 21 & 10 & 11 & & \\
\hline Microcarcinoma & & & & $<0.001^{\mathrm{a}}$ & $0.203(0.080-0.500)$ \\
\hline No & 66 & 25 & 41 & & \\
\hline Yes & 36 & 27 & 9 & & \\
\hline Histological type & & & & 0.129 & \\
\hline Classical PTC & 17 & 1 & 10 & & \\
\hline Follicular PTC & 62 & 31 & 31 & & \\
\hline Classical-Follicular PTC & 5 & 1 & 4 & & \\
\hline Unknown & 18 & 13 & 5 & & \\
\hline Tumor size (cm) & & & & $0.010^{\mathrm{a}}$ & $2.940(1.290-6.720)$ \\
\hline$<2$ & 62 & 38 & 24 & & \\
\hline$\geq 2$ & 40 & 14 & 26 & & \\
\hline Lymphovascular invasion & & & & 0.391 & $1.551(0.570-4.250)$ \\
\hline No & 83 & 44 & 39 & & \\
\hline Yes & 19 & 8 & 11 & & \\
\hline Primary tumor & & & & $0.006^{\mathrm{a}}$ & \\
\hline $\mathrm{T} 1$ & 78 & 46 & 32 & & \\
\hline $\mathrm{T} 2$ & 20 & 6 & 14 & & \\
\hline T3 & 4 & 0 & 4 & & \\
\hline TNM stage & & & & 0.114 & $0.475(0.390-0.580)$ \\
\hline I & 99 & 52 & 47 & & \\
\hline II & 3 & 0 & 3 & & \\
\hline Lymph node metastasis & & & & 1.000 & $0.510(0.050-5.810)$ \\
\hline No & 50 & 49 & & & \\
\hline Yes & 2 & 1 & & & \\
\hline Extrathyroidal extension & & & & 0.488 & $0.489(0.120-2.070)$ \\
\hline No & 93 & 46 & 47 & & \\
\hline Yes & 9 & 6 & 3 & & \\
\hline Multicentricity & & & & 0.238 & $1.629(0.720-3.68)$ \\
\hline No & 65 & 36 & 29 & & \\
\hline Yes & 37 & 16 & 21 & & \\
\hline Multifocality & & & & 0.712 & $1.160(0.530-2.550)$ \\
\hline No & 31 & 28 & & & \\
\hline Yes & 21 & 22 & & & \\
\hline
\end{tabular}

${ }^{a} \mathrm{P}<0.05$ was considered to indicate a statistically significant difference. PTC, papillary thyroid cancer.

it was hypothesized that SOX2OT might be involved in the papillary thyroid carcinoma process as it acts a miRNA sponge for miRNA-204, miRNA-122 and miRNA-132.
Xue et al (37) reported that the enhancer of zestehomolog 2 (EZH2) expression was higher in tumor samples of PTC patients compared with the normal thyroid tissue samples. 
Table II. Association between expression level of DANCR and clinicopathological characteristics of patients with PTC. Low/high decided by the median expression of DANCR. Chi square test was used for statistical analysis.

\begin{tabular}{|c|c|c|c|c|c|}
\hline \multirow[b]{2}{*}{ Characteristic } & \multirow[b]{2}{*}{ Number of patients } & \multicolumn{2}{|c|}{$\begin{array}{c}D A N C R \\
\text { expression }\end{array}$} & \multirow[b]{2}{*}{ P-value } & \multirow[b]{2}{*}{ Odds ratio $(95 \% \mathrm{CI})$} \\
\hline & & Low & High & & \\
\hline Age & & & & $0.030^{\mathrm{a}}$ & $2.645(1.090-6.450)$ \\
\hline$<45$ & 30 & 20 & 10 & & \\
\hline$\geq 45$ & 72 & 31 & 41 & & \\
\hline Sex & & & & 0.221 & $1.839(0.690-4.910)$ \\
\hline Female & 81 & 43 & 38 & & \\
\hline Male & 21 & 8 & 13 & & \\
\hline Microcarcinoma & & & & $0.004^{\mathrm{a}}$ & $0.286(0.120-0.680)$ \\
\hline No & 66 & 26 & 40 & & \\
\hline Yes & 36 & 25 & 11 & & \\
\hline Histological type & & & & 0.562 & \\
\hline Classical PTC & 17 & 10 & 7 & & \\
\hline Follicular PTC & 62 & 31 & 31 & & \\
\hline Classical-Follicular PTC & 5 & 1 & 4 & & \\
\hline Unknown & 18 & 9 & 9 & & \\
\hline Tumor size $(\mathrm{cm})$ & & & & 0.685 & $1.179(0.530-2.610)$ \\
\hline$<2$ & 62 & 32 & 30 & & \\
\hline$\geq 2$ & 40 & 19 & 21 & & \\
\hline Lymphovascular invasion & & & & 0.799 & $1.138(0.420-3.090)$ \\
\hline No & 83 & 42 & 41 & & \\
\hline Yes & 19 & 9 & 10 & & \\
\hline Primary tumor & & & & 0.693 & \\
\hline $\mathrm{T} 1$ & 78 & 41 & 37 & & \\
\hline $\mathrm{T} 2$ & 20 & 8 & 12 & & \\
\hline T3 & 4 & 2 & 2 & & \\
\hline TNM stage & & & & 1.000 & $2.041(0.180-23.240)$ \\
\hline I & 99 & 50 & 49 & & \\
\hline II & 3 & 1 & 2 & & \\
\hline Lymph node metastasis & & & & 1.000 & $2.041(0.180-23.240)$ \\
\hline No & 99 & 50 & 49 & & \\
\hline Yes & 3 & 1 & 2 & & \\
\hline Extrathyroidal extension & & & & 0.487 & $0.469(0.110-1.990)$ \\
\hline No & 93 & 45 & 48 & & \\
\hline Yes & 9 & 6 & 3 & & \\
\hline Multicentricity & & & & 0.837 & $0.919(0.410-2.060)$ \\
\hline No & 65 & 32 & 33 & & \\
\hline Yes & 37 & 19 & 18 & & \\
\hline Multifocality & & & & 0.160 & $0.567(0.260-1.270)$ \\
\hline No & 59 & 26 & 33 & & \\
\hline Yes & 43 & 25 & 18 & & \\
\hline
\end{tabular}

${ }^{\mathrm{a}} \mathrm{P}<0.05$ was considered to indicate a statistically significant difference. $\mathrm{PTC}$, papillary thyroid cancer.

SOX2OT is known to recruit EZH2 which induces $\mathrm{H} 3 \mathrm{~K} 27 \mathrm{me} 3$ and downregulates PTEN expression (10). Therefore, SOX2OT may downregulate the expression of PTEN by upregulating
EZH2 and thus might contribute to tumorigenesis of PTC. SOX2OT expression in various types of cancer has also been found to be associated with the clinicopathological 
Table III. Association between expression level of TINCR and clinicopathological characteristics of patients with PTC. Low/high decided by the median expression of TINCR. Chi square test was used for statistical analysis.

\begin{tabular}{|c|c|c|c|c|c|}
\hline \multirow[b]{2}{*}{ Characteristic } & \multirow[b]{2}{*}{ Number of patients } & \multicolumn{2}{|c|}{$T I N C R$ expression } & \multirow[b]{2}{*}{ P-value } & \multirow[b]{2}{*}{ Odds ratio $(95 \% \mathrm{CI})$} \\
\hline & & Low & High & & \\
\hline Age, years & & & & 0.385 & $1.462(0.620-3.450)$ \\
\hline$<45$ & 30 & 17 & 13 & & \\
\hline$\geq 45$ & 72 & 34 & 38 & & \\
\hline Sex & & & & 0.807 & $0.887(0.340-2.320)$ \\
\hline Female & 81 & 40 & 41 & & \\
\hline Male & 21 & 11 & 10 & & \\
\hline Microcarcinoma & & & & 0.214 & $0.595(0.260-1.350)$ \\
\hline No & 66 & 30 & 36 & & \\
\hline Yes & 36 & 21 & 15 & & \\
\hline Histological type & & & & 0.148 & \\
\hline Classical PTC & 17 & 5 & 12 & & \\
\hline Follicular PTC & 62 & 31 & 31 & & \\
\hline Classical-Follicular PTC & 5 & 4 & 1 & & \\
\hline Unknown & 18 & 11 & 7 & & \\
\hline Tumor size $(\mathrm{cm})$ & & & & 0.417 & $0.719(0.320-1.600)$ \\
\hline$<2$ & 62 & 29 & 33 & & \\
\hline$\geq 2$ & 40 & 22 & 18 & & \\
\hline Lymphovascular invasion & & & & 0.075 & $2.566(0.890-7.400)$ \\
\hline No & 83 & 45 & 38 & & \\
\hline Yes & 19 & 6 & 13 & & \\
\hline Primary tumor & & & & $0.029^{\mathrm{a}}$ & \\
\hline $\mathrm{T} 1$ & 78 & 35 & 43 & & \\
\hline $\mathrm{T} 2$ & 20 & 15 & 5 & & \\
\hline $\mathrm{T} 3$ & 4 & 1 & 3 & & \\
\hline TNM stage & & & & 1.000 & $2.041(0.180-23.240)$ \\
\hline I & 99 & 49 & 50 & & \\
\hline II & 3 & 2 & 1 & & \\
\hline Lymph node metastasis & & & & 1.000 & $2.041(0.180-23.240)$ \\
\hline No & 50 & 49 & & & \\
\hline Yes & 1 & 2 & & & \\
\hline Extrathyroidal extension & & & & 0.160 & $3.900(0.770-19.760)$ \\
\hline No & 93 & 49 & 44 & & \\
\hline Yes & 9 & 2 & 7 & & \\
\hline Multicentricity & & & & 0.837 & $0.919(0.410-2.060)$ \\
\hline No & 65 & 32 & 33 & & \\
\hline Yes & 37 & 19 & 18 & & \\
\hline Multifocality & & & & 0.547 & $0.785(0.360-1.730)$ \\
\hline No & 59 & 28 & 31 & & \\
\hline Yes & 43 & 23 & 20 & & \\
\hline
\end{tabular}

${ }^{\text {a}} \mathrm{P}<0.05$ was considered to indicate a statistically significant difference. PTC, papillary thyroid cancer.

characteristics of the patients. A study by Teng et al (38) correlated exosomal SOX2OT expression with tumor size, lymph node metastasis and TNM stage in patients with lung squamous cell carcinoma. Shi and Teng (39) determined that
SOX2OT expression was associated with histological grade, tumor number and vein invasion status in hepatocellular carcinoma. In the present study, it was found that elevated SOX2OT expression was associated with tumor type, tumor 
size and primary tumor. When the expression of SOX2OT was assessed only in micropapillary carcinoma samples (tumor size $\leq 1 \mathrm{~cm}$ ), no difference was found between the tumor and normal tissues. On the other hand, when the papillary carcinoma samples (tumor size $>1 \mathrm{~cm}$ ) were examined, it was found that the expression difference between the tumor and normal tissues was greater than in the total sample. Therefore, it might be concluded that the expression of SOX2OT increased significantly in PTC; however, the increase in tumors of $1 \mathrm{~cm}$ or below was insignificant.

In recent years, an increasing number of studies have reported abnormal $D A N C R$ expression in a number of types of cancer (18-20). It has been suggested that this abnormal expression is also associated with clinicopathological features $(19,21)$. Almost all of the studies conducted on other types of cancer (e.g. osteosarcoma, nasopharyngeal, glioma, non-small cell lung, cervical, ovarian, bladder, prostate, breast, colorectal, gastric) have reported that $D A N C R$ expression increased in tumor tissues compared with adjacent normal tissues and this elevated expression level was associated with poor prognosis $(21,40-43)$. For example, in patients with breast and colorectal cancer, DANCR expression is higher in tumor compared with normal tissue and high DANCR expression is associated with poor prognosis $(19,20)$. In the current study, $D A N C R$ expression increased significantly in the tumor samples of the 102 patients with PTC compared with their adjacent normal tissue. In addition, DANCR expression was associated with age and presence of microcarcinoma. Findings of the present study are compatible with those of the literature.

In some studies, it was found that expressions of miRNA-138, miRNA-199a, miRNA-335-5p and miRNA214 were decreased in PTC tumor samples compared with adjacent normal tissue samples and these miRNAs were identified as tumor suppressor miRNAs that served a role in suppressing proliferation, inducing apoptosis and mediating suppression of migration and invasion $(34,44)$. On the other hand, it is known that DANCR acts as a sponge for these miRNAs and reduces their expression (21). Therefore, it is hypothesized that $D A N C R$ may be involved in PTC tumorigenesis process by acting as a competing endogenous RNA (ceRNA) for these miRNAs.

Abnormal activation of the Wnt pathway and increased expression of $\beta$-catenin may cause PTC to develop (45). Some studies have suggested that DANCR may even have an oncogenic role by activating the $\beta$-catenin signaling pathway in various cancers $(16,18,43,46)$. AXL, a receptor tyrosine kinase, shows an oncogenic activity by helping regulate a number of different processes related to cancer development and progression (47). $A X L$ is highly expressed in various types of cancer including thyroid cancer (48). In some studies it has been reported that $D A N C R$ activates the PI3K/AKT/NF- $\kappa \mathrm{B}$ signaling pathway by upregulating $A X L$ (16). Therefore, $D A N C R$ may be involved in the development and progression of PTC by interacting with genes in the Wnt and PI3K/AKT pathways.

A few studies have suggested that low DANCR expression may be associated with the development of cancer $(16,21)$. Zhang et al (23) reported that DANCR expression is downregulated in tumor samples compared with the adjacent normal tissues in 76 patients with PTC and they found that DANCR expression was correlated with $\mathrm{T}$ grade and TNM stage. The findings of the present study are not compatible with that data. It is known that the roles of lncRNAs can differ from one form of cancer to another $(16,49)$. In addition, there are studies in the literature reporting different results in the same cancer type $(16,24)$. Furthermore, expressions of lncRNAs may differ in different populations (50). However, the relatively small number of patients included in such studies may also be the reason for the inconsistency between the results. In the present study, similar to SOX2OT, when the expression of DANCR was analyzed only in micropapillary carcinoma samples (tumor size $\leq 1 \mathrm{~cm}$ ), no difference was observed between the tumor and normal tissues. However, when only papillary carcinoma samples (tumor size $>1 \mathrm{~cm}$ ) were examined, it was observed that the difference between the tumor and normal tissues was greater compared with the total sample evaluation. Based on findings of the present study, it may be concluded that the expression of DANCR had increased significantly in PTC, but it did not significantly increase in tumors of $\leq 1$.

Numerous studies have reported abnormal TINCR expression in hepatocellular, colon, breast, bladder, lung, prostate, gastric, esophageal and oral squamous cell cancer (25,51-54). The expression of TINCR has been defined at the last stage of epidermal differentiation and regulates the expression of $A L O X E 3, F L G, L O R$ and $A L O X 12 B$, all of which have important roles in differentiation at the post-transcriptional level (55). Signaling pathways such as Wnt/ $\beta$-catenin, ERK1/2-SP3 and MAPK have been determined to be the targets of TINCR in different types of cancer (24). In addition, TINCR expression increases in esophageal, breast, bladder and gastric cancer, but decreases in retinoblastoma, glioma and prostate cancer $(24,52,54,56-59)$. On the other hand, it has been reported that TINCR expression is upregulated in certain studies while it is downregulated in others conducted in the same cancer type $(24,54,57-59)$. In their RNA sequencing study, You et al (26) found that TINCR expression increased in PTC tumor tissues compared with adjacent normal tissues. The findings of the present study however, showed that TINCR expression did not show a significant difference between the tumor and adjacent normal tissue samples. You et al (26) used TCGA data in their study and determined expression levels by RNA sequencing analysis. In addition, the patient group in the aforementioned study consisted of stage I, II, III and IV patients. In the present study, the patient group mostly consisted of stage I patients. Therefore, the fact that the patients included in the studies were at different stages, the use of different expression analysis methods and the limited number of patients may have led to the difference in the results.

In conclusion, results of the current study demonstrated that the expression levels of SOX2OT and DANCR increased in PTC tissues compared with their adjacent normal tissue. No significant change was observed in the expression level of TINCR. However, when the micropapillary thyroid carcinoma was examined, no significant increase was observed in the expression levels of SOX2OT or DANCR. In addition, the expression level of $S O X 2 O T$ was associated with tumor size and primary tumor. In the light of the results of the present study, it is concluded that DANCR may contribute to the development of PTC and SOX2OT may contribute to both the development and progression of PTC. One of the limitations of the present study is that the results of the expression analysis 
were not confirmed by functional studies. Another limitation is that the number of patients was relatively low. Future studies with a larger number of patients in PTC and other subgroups of thyroid cancer alongside in vitro functional studies will facilitate supporting the data of the present study.

\section{Acknowledgements}

Not applicable.

\section{Funding}

This study was supported by the Scientific Research Projects Committee of Giresun University (project numbers: SAĞ-BAP-A-150219-39).

\section{Availability of data and materials}

The datasets used and/or analyzed during the current study are available from the corresponding author on reasonable request.

\section{Authors' contributions}

FMI, EAk and DS contributed to conception and design of the study. FMI, EAk, DS and EAl performed experiments and data collection. FMI, AO and EAl performed data analysis and interpretation. FMI and AO drafted the paper. All authors contributed to the manuscript revision and read and approved the final version. FMI and EAl confirm the authenticity of all the raw data.

\section{Ethics approval and consent to participate}

This study was approved by Giresun University's Faculty of Medicine Clinical Trials Ethics Committee (approval no: 2018-06-10). All patients provided written informed consent prior to the study.

\section{Patient consent for publication}

Not applicable.

\section{Competing interests}

The authors declare that they have no competing interests.

\section{References}

1. Deng Y, Li H, Wang M, Li N, Tian T, Wu Y, Xu P, Yang S, Zhai Z, Zhou L, et al: Global burden of thyroid cancer from 1990 to 2017. JAMA Netw Open 3: e208759, 2020.

2. Cao J,Zhang M,Zhang L, Lou J, Zhou F and Fang M: Non-coding RNA in thyroid cancer-Functions and mechanisms. Cancer Lett 496: 117-126, 2021.

3. Javed Z, Ahmed Shah F, Rajabi S, Raza Q, Iqbal Z, Ullah M, Ahmad T, Salehi B, Sharifi-Rad M, Pezzani R, et al: LncRNAs as potential therapeutic targets in thyroid cancer. Asian Pac J Cancer Prev 21: 281-287, 2020.

4. Peng X, Zhang K, Ma L, Xu J and Chang W: The Role of long non-coding RNAs in thyroid cancer. Front Oncol 10: 941, 2020.

5. Liyanarachchi S, Gudmundsson J, Ferkingstad E, He H, Jonasson JG, Tragante V, Asselbergs FW, Xu L, Kiemeney LA, Netea-Maier RT, et al: Assessing thyroid cancer risk using polygenic risk scores. Proc Natl Acad Sci USA 117: 5997-6002, 2020
6. Zhang Y, Jin T, Shen H, Yan J, Guan M and Jin X: Identification of long non-coding RNA expression profiles and Co-expression genes in thyroid carcinoma based on the cancer genome atlas (TCGA) database. Med Sci Monit 25: 9752-9769, 2019.

7. Ghafouri-Fard S, Mohammad-Rahimi $\mathrm{H}$ and Taheri M: The role of long non-coding RNAs in the pathogenesis of thyroid cancer. Exp Mol Pathol 112: 104332, 2020.

8. Mahmoudian-Sani MR, Jalali A, Jamshidi M, Moridi H, Alghasi A, Shojaeian A and Mobini GR: Long non-coding RNAs in thyroid cancer: Implications for pathogenesis, diagnosis, and therapy. Oncol Res Treat 42: 136-142, 2019.

9. Chang X, Zhang H, Yang Q and Pang L: LncRNA SOX2OT affects cervical cancer cell growth, migration and invasion by regulating SOX2. Cell Cycle 19: 1391-1403, 2020.

10. Wang $\mathrm{Y}, \mathrm{Wu} \mathrm{N}$, Luo $\mathrm{X}$, Zhang $\mathrm{X}$, Liao Q and Wang J: SOX2OT, a novel tumor-related long non-coding RNA. Biomed Pharmacother 123: 109725, 2020.

11. Li PY, Wang P, Gao SG and Dong DY: Long Noncoding RNA SOX2-OT: Regulations, functions, and roles on mental Illnesses, cancers, and diabetic complications. Biomed Res Int 2020: $2901589,2020$.

12. Zhan Y, Chen Z, He S, Gong Y, He A, Li Y, Zhang L, Zhang X, Fang D, Li X and Zhou L: Long non-coding RNA SOX2OT promotes the stemness phenotype of bladder cancer cells by modulating SOX2. Mol Cancer 19: 25, 2020.

13. Wei CX, Wong H, Xu F, Liu Z, Ran L and Jiang RD: IRF4-induced upregulation of IncRNA SOX2-OT promotes cell proliferation and metastasis in cholangiocarcinoma by regulating SOX2 and PI3K/AKT signaling. Eur Rev Med Pharmacol Sci 22: 8169-8178, 2018.

14. Li Z, Jiang P, Li J, Peng M, Zhao X, Zhang X, Chen K, Zhang Y, Liu H, Gan L, et al: Tumor-derived exosomal lnc-Sox 2 ot promotes EMT and stemness by acting as a ceRNA in pancreatic ductal adenocarcinoma. Oncogene 37: 3822-3838, 2018

15. Kretz M, Webster DE, Flockhart RJ, Lee CS, Zehnder A, Lopez-Pajares V, Qu K, Zheng GX, Chow J, Kim GE, et al: Suppression of progenitor differentiation requires the long noncoding RNA ANCR. Genes Dev 26: 338-343, 2012.

16. Pan L, Xiao X, Zhao Y, Yin L, Fu M, Zhang X and Jiang P: The functional roles of long noncoding RNA DANCR in Human Cancers. J Cancer 11: 6970-6981, 2020.

17. Hao YP, Qiu JH, Zhang DB and Yu CG: Long non-coding RNA DANCR, a prognostic indicator, promotes cell growth and tumorigenicity in gastric cancer. Tumour Biol: Jun 15, 2017 (Epub ahead of print). doi: 10.1177/1010428317699798.

18. Ma X, Wang X, Yang C, Wang Z, Han B, Wu L and Zhuang L: DANCR Acts as a diagnostic biomarker and promotes tumor growth and metastasis in hepatocellular carcinoma. Anticancer Res 36: 6389-6398, 2016.

19. Liu Y, Zhang M, Liang L, Li J and Chen YX: Over-expression of lncRNA DANCR is associated with advanced tumor progression and poor prognosis in patients with colorectal cancer. Int J Clin Exp Pathol 8: 11480, 2015.

20. Tao W, Wang C, Zhu B, Zhang G and Pang D: LncRNA DANCR contributes to tumor progression via targetting miR-216a-5p in breast cancer: LncRNA DANCR contributes to tumor progression. Biosci Rep 39: BSR20181618, 2019.

21. Yan Y, Shi Q, Yuan X, Xue C, Shen S and He Y: DANCR: An emerging therapeutic target for cancer. Am J Transl Res 12: 4031-4042, 2020

22. Li Z, Hou P, Fan D, Dong M, Ma M, Li H, Yao R, Li Y, Wang G, Geng P, et al: The degradation of EZH2 mediated by lncRNA ANCR attenuated the invasion and metastasis of breast cancer. Cell Death Differ 24: 59-71, 2017.

23. Zhang K, Lv J, Peng X, Liu J, Li C, Li J, Yin N, Li H and Li Z: Down-regulation of DANCR acts as a potential biomarker for papillary thyroid cancer diagnosis. Biosci Rep: Apr 23, 2019 (Epub ahead of print). doi: 10.1042/BSR20181618.

24. Ghafouri-Fard S, Dashti S, Taheri M and Omrani MD: TINCR An lncRNA with dual functions in the carcinogenesis process. Non-coding RNA Res 5: 109-115, 2020.

25. Sharma U, Barwal TS, Malhotra A, Pant N, Vivek, Dey D, Gautam A, Tuli HS, Vasquez KM and Jain A: Long non-coding RNA TINCR as potential biomarker and therapeutic target for cancer. Life Sci 257: 118035, 2020.

26. You X, Zhao Y, Sui J, Shi X, Sun Y, Xu J, Liang G, Xu Q and Yao Y: Integrated analysis of long noncoding RNA interactions reveals the potential role in progression of human papillary thyroid cancer. Cancer Med 7: 5394-5410, 2018. 
27. Livak KJ and Schmittgen TD: Analysis of relative gene expression data using real-time quantitative PCR and the 2(-Delta Delta C(T)) method. Methods 25: 402-408, 2001.

28. Fu XM, Guo W, Li N, Liu HZ, Liu J, Qiu SQ, Zhang Q, Wang LC, $\mathrm{Li} \mathrm{F}$ and $\mathrm{Li} \mathrm{CL}$ : The expression and function of long noncoding RNA lncRNA-ATB in papillary thyroid cancer. Eur Rev Med Pharmacol Sci 21: 3239-3246, 2017.

29. Han CG, Huang Y and Qin L: Long Non-Coding RNA ZFAS1 as a novel potential biomarker for predicting the prognosis of thyroid cancer. Med Sci Monit 25: 2984-2992, 2019.

30. Bolha L, Ravnik-Glavač M and Glavač D: Long noncoding RNAs as biomarkers in cancer. Dis Markers 2017: 7243968, 2017.

31. Huarte M: The emerging role of lncRNAs in cancer. Nat Med 21: $1253-1261,2015$

32. Amaral PP, Neyt C, Wilkins SJ, Askarian-Amiri ME, Sunkin SM, Perkins AC and Mattick JS: Complex architecture and regulated expression of the Sox 2 ot locus during vertebrate development. RNA 15: 2013-2027, 2009.

33. Zhang E and Li X: LncRNA SOX2-OT regulates proliferation and metastasis of nasopharyngeal carcinoma cells through miR-146b-5p/HNRNPA2B1 pathway. J Cell Biochem 120 16575-16588, 2019.

34. Santiago K, Chen Wongworawat $Y$ and Khan S: Differential MicroRNA-signatures in thyroid cancer subtypes. J Oncol 2020: 2052396, 2020.

35. Hu N, Tian Y, Song Y and Zang L: miR-122-5p suppresses the oncogenesis of PTC by inhibiting DUSP4 expression. Mol Med Rep 23: 368, 2021

36. Chen X, Li M, Zhou H and Zhang L: miR-132 Targets FOXA1 and exerts tumor-suppressing functions in thyroid cancer. Oncol Res 27: 431, 2019.

37. Xue L, Yan H, Chen Y, Zhang Q, Xie X, Ding X, Wang X, Qian Z, Xiao F, Song Z, et al: EZH2 upregulation by ER $\alpha$ induces proliferation and migration of papillary thyroid carcinoma. BMC Cancer 19: 1094, 2019.

38. Teng $\mathrm{Y}$, Kang $\mathrm{H}$ and $\mathrm{Chu} \mathrm{Y}$ : Identification of an exosomal long noncoding RNA SOX2-OT in plasma as a promising biomarker for lung squamous cell carcinoma. Genet Test Mol Biomarkers 23 235-240, 2019.

39. Shi XM and Teng F: Up-regulation of long non-coding RNA Sox 2ot promotes hepatocellular carcinoma cell metastasis and correlates with poor prognosis. Int J Clin Exp Pathol 8 : 4008-4014, 2015.

40. Wang S and Jiang M: The long non-coding RNA-DANCR exerts oncogenic functions in non-small cell lung cancer via miR-758-3p. Biomed Pharmacother 103: 94-100, 2018.

41. Pan Z, Wu C, Li Y, Li H, An Y, Wang G, Dai J and Wang Q: LncRNA DANCR silence inhibits SOX5-medicated progression and autophagy in osteosarcoma via regulating miR-216a-5p. Biomed Pharmacother 122: 109707, 2020.

42. Li Q, Jiang Y, Zhong G, Lu Y, Song T, Zhang Y, Wu J, Zhang M, Liang X, Zhou L, et al: Long noncoding RNA DANCR regulates cell proliferation by stabilizing SOX2 mRNA in nasopharyngeal carcinoma. Am J Pathol 190: 2343-2354, 2020

43. Li J and Zhou L: Overexpression of IncRNA DANCR positively affects progression of glioma via activating Wnt $/ \beta$-catenin signaling. Biomed Pharmacother 102: 602-607, 2018.

44. Hitu L, Gabora K, Bonci EA, Piciu A, Hitu AC, Stefan PA and Piciu D: MicroRNA in papillary thyroid carcinoma: A systematic review from 2018 to June 2020. Cancers (Basel) 12: 3118, 2020.

45. Lu HW and Liu XD: UCA1 promotes papillary thyroid carcinoma development by stimulating cell proliferation via Wnt pathway. Eur Rev Med Pharmacol Sci 22: 5576-5582, 2018.
46. Pan L, Liang W, Gu J, Zang X, Huang Z, Shi H, Chen J, Fu M, Zhang P, Xiao X, et al: Long noncoding RNA DANCR is activated by SALL4 and promotes the proliferation and invasion of gastric cancer cells. Oncotarget 9: 1915-1930, 2017.

47. Vouri M and Hafizi S: TAM Receptor tyrosine kinases in cancer drug resistance. Cancer Res 77: 2775-2778, 2017.

48. Collina F, La Sala L, Liotti F, Prevete N, La Mantia E, Chiofalo MG, Aquino G, Arenare L, Cantile M, Liguori G, et al: AXL Is a novel predictive factor and therapeutic target for radioactive iodine refractory thyroid cancer. Cancers (Basel) 11: 785, 2019.

49. Liu XF, Hao JL, Xie T, Pant OP, Lu CB, Lu CW and Zhou DD: The BRAF activated non-coding RNA: A pivotal long non-coding RNA in human malignancies. Cell Prolif 51: e12449, 2018.

50. Pahlevan Kakhki M, Rakhshi N, Emami Aleagha MS, Abdari M, Alikhah A, Safarian G, Behmanesh $M$ and Nikravesh A: Differential expression of STAT3 gene and its regulatory long non-coding RNAs, namely lnc-DC and THRIL, in two eastern Iranian ethnicities with multiple sclerosis. Neurol Sci 41: $561-568,2020$

51. Chen F, Qi S, Zhang X, Wu J, Yang X and Wang R: lncRNA PLAC2 activated by H3K 27 acetylation promotes cell proliferation and invasion via the activation of $\mathrm{Wnt} / \beta$-catenin pathway in oral squamous cell carcinoma. Int J Oncol 54: 1183-1194, 2019.

52. Chen Z, Liu H, Yang H, Gao Y, Zhang G and Hu J: The long noncoding RNA, TINCR, functions as a competing endogenous RNA to regulate PDK1 expression by sponging miR-375 in gastric cancer. Onco Targets Ther 10: 3353-3362, 2017.

53. Tian F, Xu J, Xue F, Guan E and Xu X: TINCR expression is associated with unfavorable prognosis in patients with hepatocellular carcinoma. Biosci Rep 37: BSR20170301, 2017.

54. Zhu ZJ and He JK: TINCR facilitates non-small cell lung cancer progression through BRAF-activated MAPK pathway. Biochem Biophys Res Commun 497: 971-977, 2018.

55. Kretz M, Siprashvili Z, Chu C, Webster DE, Zehnder A, Qu K, Lee CS, Flockhart RJ, Groff AF, Chow J, et al: Control of somatic tissue differentiation by the long non-coding RNA TINCR. Nature 493: 231-235, 2013.

56. Song L, Qi Y and Lin M: Long noncoding RNA PLAC2 regulates PTEN in retinoblastoma and participates in the regulation of cancer cell apoptosis. Oncol Lett 19: 2489-2494, 2020.

57. Xia $\mathrm{H}$, Xiu M, Gao J and Jing $\mathrm{H}$ : LncRNA PLAC 2 downregulated miR-21 in non-small cell lung cancer and predicted survival. BMC Pulm Med 19: 172, 2019.

58. Xu Y, Qiu M, Chen Y, Wang J, Xia W, Mao Q, Yang L, Li M, Jiang F, Xu L and Yin R: Long noncoding RNA, tissue differentiation-inducing nonprotein coding RNA is upregulated and promotes development of esophageal squamous cell carcinoma. Dis Esophagus 29: 950-958, 2016.

59. Zhang ZY, Lu YX, Zhang ZY, Chang YY, Zheng L, Yuan L, Zhang F, Hu YH, Zhang WJ and Li XN: Loss of TINCR expression promotes proliferation, metastasis through activating EpCAM cleavage in colorectal cancer. Oncotarget 7: 22639-22649, 2016

This work is licensed under a Creative Commons Attribution-NonCommercial-NoDerivatives 4.0 International (CC BY-NC-ND 4.0) License. 